\title{
Cachieliach
}

\section{Zlusgewählte Sđhachhumoresten}

Don

\section{paul S Ş̧enenbera}

\author{
3weite, oerăderte Uuflage
}

Mit zaḩlreid̨en Diagrammen

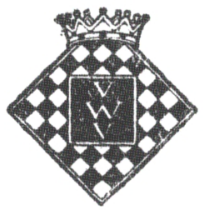

Berlin und Seipjig 1921

Vereinigung wiffenfhaftlider Derleger walter de Grapter \& $\mathbb{C}_{0}$.

oormals B. J. Bofdien'fhe Derlagshanding - 3. Buttentag, Derlagss budhandlang - Beorg Reimer - Karl J. Erabner - Deit \& Comp. 


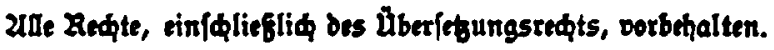

